\title{
The burden of major adverse cardiac events in patients with coronary artery disease
}

I-Ting Tsai ${ }^{1,8}$, Chao-Ping Wang ${ }^{2,7}$, Yung-Chuan Lu, ${ }^{3,7}$, Wei-Chin Hung ${ }^{2}$, Cheng-Ching Wu ${ }^{2,9}$, Li-Fen Lư Fu-Mei Chung ${ }^{2}$, Chia-Chang Hsu ${ }^{4}$, Yau-Jiunn Lee ${ }^{6}$ and Teng-Hung Yu ${ }^{2 *}$

\begin{abstract}
Background: Patients with a history of cardiovascular disease are at high risk of developing secondary major adverse cardiac events (MACE). This study aimed to identify independent predictors of MACE after hospital admission which could be used to identify of high-risk patients who may benefit from preventive strategies.

Methods: This study included 1,520 consecutive patients with coronary artery disease (CAD) (654 with acute coronary syndrome (ACS) and 866 with elective percutaneous coronary intervention (PCI) patients) who received $\mathrm{PCl}$ and/or stenting. MACE was defined as all-cause mortality or rehospitalization for a cardiovascular- related illness. Cardiovascular-related illnesses included heart failure, reinfarction (nonfatal), recurrence of angina pectoris and repeat $\mathrm{PCl}$ or coronary artery bypass graft.

Results: During a mean follow-up period of 32 months, 558 of the 1,520 patients developed at least one MACE. Cox regression analysis showed that the baseline clinical and biochemical variables which associated with MACE were age, being illiterate, a widow or widower, and/or economically dependent, having triple vessel disease, stent implantation, anemia, and/or diabetes mellitus, waist to hip ratio (WHR), diastolic blood pressure, fasting glucose, total cholesterol, high-density lipoprotein cholesterol (HDL-C), creatinine, estimated glomerular filtration rate (eGFR), red blood cell count, hemoglobin, hematocrit, and mean corpuscular-hemoglobin concentration (MCHC) in ACS patients, and age, malnourished, and/or economically dependent, taking hypoglycemic medication, having triple vessel disease, stent implantation, anemia, diabetes mellitus, and/or hypertension, WHR, fasting glucose, HDL-C, uric acid, creatinine, eGFR, high-sensitivity C-reactive protein, mean corpuscular volume, and MCHC in elective PCl patients. Using multivariate Cox regression analysis, we found the MACE's independent factors are triple vessel disease, stent implantation, hypertension, and eGFR in ACS patients, and having triple vessel disease, stent implantation, hypertension, and uric acid in elective PCl patients.
\end{abstract}

Conclusions: Having triple vessel disease, stent implantation, hypertension, and eGFR or uric acid independently predicted MACE in patients with CAD after long-term follow-up. Fortunately, these factors are modifiable and should be identified and monitored early.

Keywords: Major adverse cardiovascular events, Predictive factors, Coronary artery disease

\footnotetext{
* Correspondence: gene6623@yahoo.com.tw; tenghungy@yahoo.com.tw

2Division of Cardiology, E-Da Hospital, I-Shou University, No. 1, Yi-Da Rd,

Jiau-Shu Village, Yan-Chao District, Kaohsiung 82445, Taiwan

Full list of author information is available at the end of the article
}

(c) The Author(s). 2017 Open Access This article is distributed under the terms of the Creative Commons Attribution 4.0 International License (http://creativecommons.org/licenses/by/4.0/), which permits unrestricted use, distribution, and reproduction in any medium, provided you give appropriate credit to the original author(s) and the source, provide a link to the Creative Commons license, and indicate if changes were made. The Creative Commons Public Domain Dedication waiver (http://creativecommons.org/publicdomain/zero/1.0/) applies to the data made available in this article, unless otherwise stated. 


\section{Background}

Coronary artery disease (CAD) is a major health problem worldwide including Taiwan, and it is expected to be the leading cause of death by 2020 [1-3]. With advances in both coronary artery bypass graft (CABG) surgery and percutaneous coronary intervention (PCI), mortality from CAD has significantly decreased [4]. Moreover, PCI or PCI with stenting and CABG were associated with a longterm safety profile and improving patient outcomes $[5,6]$. However, the poor prognosis and high cost of medical care for patients with CAD impose a considerable burden on both their families and society. Therefore, identifying risk factors that affect the prognosis of patients undergoing revascularization is necessary.

Major adverse cardiac events (MACE) are important causes of morbidity and mortality in CAD patients undergoing PCI. The detection and treatment of the risk factors for MACE are critical to improve health and longevity. As expected, the traditional risk factors (e.g. age, sex, total cholesterol, low-density lipoprotein (LDL) cholesterol, high-density lipoprotein (HDL) cholesterol, systolic blood pressure, and smoking) [7] for CAD are associated with disease progression. Using Intravascular ultrasound monitoring of changes in atheroma burden in 3,473 patients, Chhatriwalla et al. demonstrated that the patients with a very low LDL level $(\leq 70 \mathrm{mg} / \mathrm{dL})$ and normal systolic blood pressure (SBP) $(\leq 120 \mathrm{mmHg}$ ) had the slowest CAD progression [8]. In addition, in patients with LDL levels $\leq 70 \mathrm{mg} / \mathrm{dL}$, progression of native coronary atherosclerotic disease was associated with the presence of residual risk factors including high baseline glucose levels, increased level of triglycerides, and small decrease in apolipoprotein B [9]. Previous study also reported that baseline diabetes was the strongest significant cardiovascular disease-related factor for disease progression [10]. Therefore, the purpose of this study was to evaluate whether baseline risk factors such as demographic and clinical characteristics, lipid levels, inflammation, triple vessel disease, stent implantation, anemia, diabetes mellitus (DM), hypertension, and chronic kidney disease (CKD) were associated with the development of MACE in patients with CAD receiving PCI. The results could be important in increasing physicians' awareness on the importance of regular baseline risk factors screening when caring for patients with CAD.

\section{Methods \\ Study Subjects}

In this prospective study, from June 2007 to June 2015, we studied 1,644 patients with CAD who made consecutive visits to the Taiwan I-Shout University E-Da Hospital's Emergency Room and Cardiovascular Clinic (Fig. 1). All

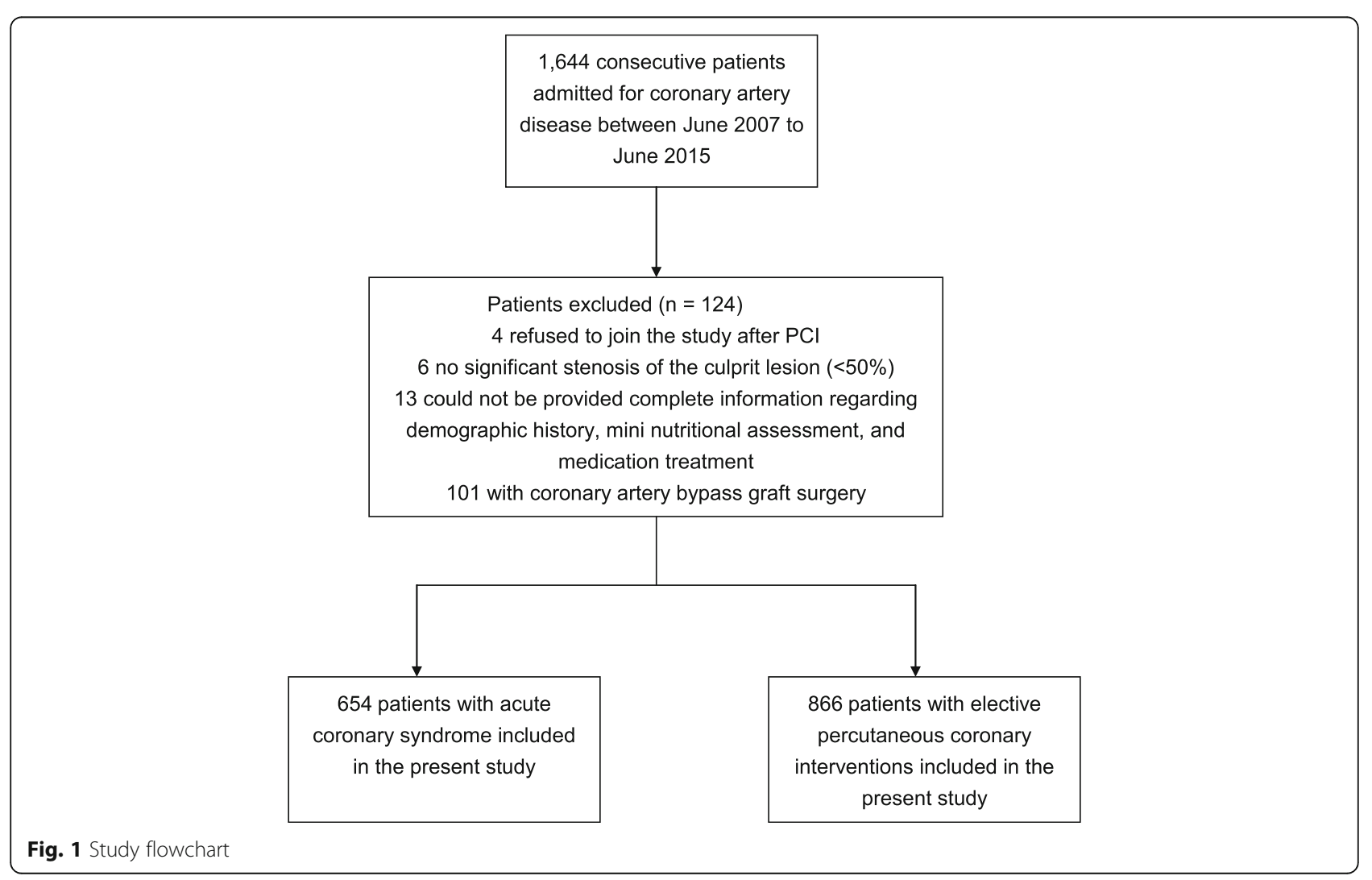


the demographic data, clinical information, and current medications of the patients were examined and recorded by two healthcare professionals with expertise in CAD care, via a web-based case report form in the clinical data management system of the E-Da Hospital, with special attention being paid to cardiovascular risk factors and co-morbidities. The clinical data system at the E-Da Hospital documented all the clinical consecutive variables and values when patient admitted to the Cardiovascular Clinic or Ward due to CAD or other heart diseases. Age, sex, smoking habits, hyperlipidemia, arterial hypertension, $\mathrm{DM}, \mathrm{CAD}$, history of stroke and acute myocardial infarction were evaluated. Medical history survey, physical examinations, blood test, and urinalysis were conducted. Patients presenting with stage $5 \mathrm{CKD}$, concomitant inflammatory diseases such as infection or sepsis, and other medical history of malignancy, liver disease or collagen disease, those using steroids, and those who had undergone any type of surgery in the month prior to admission or refused to participate in the study were excluded. Data were evaluated on the day of patients discharge after interobserver agreement gained. In cases of discrepancy, reevaluation by both investigators and a consensus was performed. To detect undiagnosed diabetes, fasting blood glucose concentration was determined at admission. During the hospital stay, repeat blood pressure measurements were conducted to discover undiagnosed hypertension. Written informed consent was given by each CAD patient before enrollment. If patients were unable to give consent because of disease severity, informed consent was obtained from a relative or legal representative. The study protocol and informed consent procedure were approved by the Ethics Committee of I-Shou University E-Da Hospital.

\section{Laboratory Measurements}

Plasma biochemical parameters were measured after an overnight fast. Levels of plasma triglycerides, total cholesterol, LDL-cholesterol, HDL-cholesterol, uric acid, creatinine, and glucose were determined by standard commercial methods using a parallel-multichannel analyzer (Hitachi 7170A, Tokyo, Japan), as described previously [11]. Levels of plasma C-reactive protein (CRP) were measured using a high-sensitivity method (IMMAGE; Beckman Coulter, Immunochemistry Systems, Brea, CA) with a detection limit of $0.2 \mathrm{mg} / \mathrm{L}$. The intra-assay coefficient of variation was $4.2 \%$ to $8.7 \%$ for high-sensitivity CRP (hs-CRP). Samples were measured in duplicate in a single experiment. Estimated glomerular filtration rate (eGFR) was calculated using the CKD-EPI two-level race equation [12]. Anthropometric parameters including body mass index (BMI) and waist to hip ratio (WHR) were measured. Waist and hip circumferences were measured to the nearest $0.1 \mathrm{~cm}$ at the narrowest point between the lowest rib and the uppermost lateral border of the right iliac crest. Hips were measured at their widest point. Seated blood pressure was measured by a trained nurse with a digital automatic blood pressure monitor (model HEM-907; Omron, Omron, Japan) after the subjects had rested for 5 minutes.

\section{Study End-points}

The patients were followed-up after admission using a standardized protocol that included outpatient visits, telephone contact and the recording of recurrent cardiac events. The endpoints were the composite occurrence of MACE, including all-cause mortality or re-hospitalization for a cardiovascular-related illness. Cardiovascular-related illnesses included heart failure, reinfarction (nonfatal), recurrence of angina pectoris and repeat PCI or CABG [13]. The heart failure endpoint was investigated on the basis of clinical parameters suggestive of pulmonary congestion and/or signs of low cardiac output. Angina was definitions of dull diffuse substernal chest discomfort precipitated by exertion or emotion and relieved by rest or nitroglycerin. Non-fatal reinfarction was defined as angina or anginal equivalent accompanied by a new ST-segment elevation in leads consistent with those of the territory of the artery affected in the index event. Revascularization was characterized by the need for percutaneous or surgical intervention motivated by instability of the clinical picture (elective revascularization were not considered endpoints).

\section{Follow-up}

The patients were clinically reevaluated at 3,6 , and 12 months after hospital discharge and then annually until June 2015. All participants had entered a disease management program at our Cardiovascular Clinic. All of the patients received a follow-up questionnaire from a trained nurse during June 2015 to re-evaluate the occurrence of MACE during the whole follow-up period. For the patients did not respond to the questionnaire, personal telephone contact was made. In addition, all hospital discharge reports relating to any other re-admission during the follow-up period were also been reviewed. The performance of PCI and CABG was validated by reviewing the original procedure protocols. Outcomes were assessed by two research physicians with expertise in Cardiology; they have 11 years clinical experience in catheriterization procedure and were active member of the Taiwan Society of Cardiology. Two research physicians were blinded to the patients' all baseline clinical data. In case of disagreement, consensus was sought. Finally, a cardiovascular interventionist, whose judgment was considered decisive, reviewed all events. In addition, the type of objective information included medical records, radiography, reports of cardiac catheterization, EKG, and cardiac echo, and pathology that were 
provided the adjudicators to make their assessments according to the endpoint definitions.

\section{Definitions}

In our study, the diagnosis of CAD was confirmed by coronary angiography. Significant coronary stenosis was defined as a vessel luminal diameter decrease of greater than or equal to $70 \%$ in either one of 15 coronary segments. If PCI was considered, balloon angioplasty or stenting was performed according the vessel condition. However, for left main and severe triple vessel disease, CABG was suggested to the patients. Hypertension was defined as systolic blood pressure of $\geq 140 \mathrm{mmHg}$, diastolic blood pressure of $\geq 90 \mathrm{mmHg}$ or both, or the use of anti-hypertensive drugs. Hyperlipidemia was defined as a triglyceride level $\geq 150 \mathrm{mg} / \mathrm{dL}$, and/or a HDL-cholesterol level of $<35 \mathrm{mg} / \mathrm{dL}$ for men and $<39 \mathrm{mg} / \mathrm{dL}$ for women, and/or a total cholesterol level of $\geq 200 \mathrm{mg} / \mathrm{dL}$, and/or a LDL-cholesterol level of $\geq 130 \mathrm{mg} / \mathrm{dL}$, or those undergoing treatment for lipid disorders according to the ATP III criteria [14]. DM was defined as a glucose level $>126 \mathrm{mg} / \mathrm{dl}$ [15], or having received treatment for DM. Malnutrition indicator score was defined as normal nutritional status 24 to 30 points, at risk of malnutrition 17 to 23.5 points, and malnourished less than 17 points using the Mini Nutritional Assessment. Patients' smoking status was classified as never having smoked, former smoker (ceased smoking for at least 1 year), or current smoker. In this study, former and current smokers were analyzed as a group and compared with those who had never smoked.

\section{Statistical Analysis}

Continuous variables were presented as mean $\pm S D$, and categorical variables as a percentage of the total. All statistical analyses were performed using SAS software version 10.0 (SAS Institute, Cary, NC). Baseline characteristics of the patients with MACE and without MACE were compared using the Student's $t$ test or $\chi^{2}$ test. Cox regression univariate analysis was performed. The outcome was defined as the time elapsed until the development of the MACE, and all the patients were followed until they developed a MACE. Hazard ratios (HRs) with 95\% confidence intervals were estimated by Cox proportional hazards model. The variables with a $p$ value less than 0.25 in the univariate Cox regression analysis were entered into the multivariate model. The proportional hazards assumption was further verified by Schoenfeld residuals analysis and assessment of the survival function versus the survival time graph. Model discrimination was assessed by area under the receiver operating characteristic (ROC) curve (AUC) analysis, which is a measure of overall predictive discrimination. The AUC is an overall summary of diagnostic accuracy. AUC equals 0.5 when the ROC curve corresponds to random chance and 1.0 for perfect accuracy. On rare occasions, the estimated AUC is $<0.5$, indicating that the test does worse than chance [16]. All of the statistical analyses were twosided, and a $p$ value less than 0.05 was considered to be significant.

\section{Results}

Among 1,644 consecutive CAD patients, 124 were excluded due to the following reasons: four patients refused to join the study after PCI, six patients had no significant stenosis of the culprit lesion $(<50 \%)$, one hundred and one with coronary artery bypass graft surgery, and 13 patients could not be provided complete information regarding demographic history, mini nutritional assessment, and medication treatment. The final study population included 1,520 patients (654 with ACS and 866 with elective PCI patients; Fig. 1). Of the 1,520 patients, $1,107(72.8 \%)$ men and $413(27.2 \%)$ women, mean age of patients is $69 \pm 12$ years (range, 30 to 99 years). 582 (38.3\%) had DM, 949 (62.4\%) had hyperlipidemia, and 1,092 (71.8\%) had hypertension (Tables 1 and 2).

\section{Baseline Characteristics}

All patients received clinical follow-up with a median duration of 23 months (interquartile range: 5-55 months). During the follow-up period, the incidence of MACE was $36.7 \%$ (558 of 1,520 patients). The baseline clinical characteristics and data for all of the patients are presented in Table 1. The patients who developed a MACE had higher rates of illiteracy, at risk of malnutrition, malnourished, being economically dependent, taking statins and hypoglycemic medications, and/or having triple vessel disease, stent implantation, anemia, DM, hypertension, and cause of admission for ACS than the patients without a MACE. In addition, the patients who developed a MACE were older and had a higher waist circumference, WHR, HbA1C, fasting glucose, creatinine, uric acid, hsCRP, white blood cell count, lower diastolic blood pressure, HDL-cholesterol, eGFR, red blood cell count, hemoglobin, hematocrit, mean corpuscular-hemoglobin concentration $(\mathrm{MCHC})$, and malnutrition indicator score than the patients without a MACE (Table 2). Additionally, there was no statistically significant difference in rate of MACE among 4 operators $(37.7 \%$ vs. $34.1 \%$ vs. vs. $39.7 \%$ vs. $42.7 \%, p=0.105)$.

\section{Association of the Baseline Clinical and Biochemical Risk Factors for the Development of MACE}

After univariate Cox regression analysis, the baseline clinical and biochemical variables associated with MACE were age, being illiterate, a widow or widower, economically dependent, having triple vessel disease, stent implantation, anemia, and DM, WHR, diastolic blood pressure, fasting 
Table 1 Baseline characteristics and clinical data of the study participants with and without major adverse cardiovascular events

\begin{tabular}{|c|c|c|c|c|}
\hline Variable & $\begin{array}{l}\text { Total } \\
n(\%)\end{array}$ & $\begin{array}{l}\text { With MACE } \\
n(\%)\end{array}$ & $\begin{array}{l}\text { Without MACE } \\
n(\%)\end{array}$ & $P$ value \\
\hline No & 1520 & $558(36.7)$ & $962(63.3)$ & \\
\hline \multicolumn{5}{|l|}{ Gender } \\
\hline Women & $413(27.2)$ & $140(25.1)$ & $273(28.4)$ & 0.165 \\
\hline Men & $1107(72.8)$ & $418(74.9)$ & $689(71.6)$ & 0.165 \\
\hline \multicolumn{5}{|l|}{ Education } \\
\hline Illiterate & $256(16.8)$ & $120(21.5)$ & $136(14.1)$ & 0.002 \\
\hline Elementary school & $586(38.6)$ & $228(40.9)$ & $358(37.2)$ & 0.240 \\
\hline Junior high school & $225(14.8)$ & 77 (13.8) & $148(15.4)$ & 0.497 \\
\hline High school & $336(22.1)$ & $96(17.2)$ & $240(24.9)$ & 0.003 \\
\hline College & $119(7.8)$ & $38(6.8)$ & $81(8.4)$ & 0.315 \\
\hline \multicolumn{5}{|l|}{ Marital status } \\
\hline Single & $54(3.6)$ & $18(3.2)$ & $36(3.7)$ & 0.695 \\
\hline Married & $1222(80.4)$ & $442(79.2)$ & $780(81.1)$ & 0.405 \\
\hline Divorced & $54(3.6)$ & $18(3.2)$ & $36(3.7)$ & 0.695 \\
\hline Widow or widower & $187(12.3)$ & $80(14.3)$ & $107(11.1)$ & 0.121 \\
\hline \multicolumn{5}{|l|}{ Mini nutritional assessment } \\
\hline Normal nutritional status & $1082(71.2)$ & $326(58.4)$ & $756(78.6)$ & 0.001 \\
\hline At risk of malnutrition & $376(24.7)$ & $184(33.0)$ & $192(20.0)$ & 0.025 \\
\hline Malnourished & $61(4.0)$ & $48(8.6)$ & $13(1.4)$ & 0.009 \\
\hline Economic situation, dependent & $766(50.4)$ & $336(60.2)$ & $430(44.7)$ & $<0.0001$ \\
\hline Smoking & $722(47.5)$ & $267(47.9)$ & $455(47.3)$ & 0.809 \\
\hline Drinking & $463(30.5)$ & $164(29.4)$ & $299(31.1)$ & 0.503 \\
\hline Regular exercise & $617(40.6)$ & $219(39.3)$ & $398(41.4)$ & 0.488 \\
\hline Antihypertensive medication & $824(54.2)$ & $312(55.9)$ & $512(53.2)$ & 0.310 \\
\hline Statin & $487(32.0)$ & $201(36.0)$ & $286(29.7)$ & 0.011 \\
\hline Hypoglycemic medication & $223(14.7)$ & $108(19.4)$ & $115(12.0)$ & $<0.0001$ \\
\hline Triple vessel disease & 435 (28.6) & $228(40.9)$ & $207(21.5)$ & $<0.0001$ \\
\hline Stents placed & $444(29.2)$ & $198(35.5)$ & $246(25.6)$ & $<0.0001$ \\
\hline Anemia & $356(23.4)$ & $155(27.8)$ & $201(20.9)$ & 0.003 \\
\hline Diabetes mellitus & $582(38.3)$ & $260(46.6)$ & $322(33.5)$ & $<0.0001$ \\
\hline Hypertension & $1092(71.8)$ & $435(78.0)$ & $657(68.3)$ & $<0.0001$ \\
\hline Hyperlipidemia & $949(62.4)$ & $364(65.2)$ & $585(60.8)$ & 0.088 \\
\hline \multicolumn{5}{|l|}{ Cause of admission } \\
\hline Acute coronary syndrome & $654(43.0)$ & $311(55.7)$ & $343(35.7)$ & $<0.0001$ \\
\hline Elective PCl & $866(57.0)$ & $247(44.3)$ & $619(64.4)$ & $<0.0001$ \\
\hline
\end{tabular}

MACE major adverse cardiovascular events; $P C l$ percutaneous coronary intervention

glucose, total cholesterol, HDL-cholesterol, creatinine, eGFR, red blood cell count, hemoglobin, hematocrit, and $\mathrm{MCHC}$ in ACS patients, and age, malnourished, economically dependent, taking hypoglycemic medication, having triple vessel disease, stent implantation, anemia, DM, and hypertension, WHR, fasting glucose, HDL-C, uric acid, creatinine, eGFR, high-sensitivity Creactive protein, mean corpuscular volume, and $\mathrm{MCHC}$ in elective PCI patients. Using multivariate Cox regression analysis, we found the independent factors associated with the development of MACE were triple vessel disease [HR 3.66 (1.38-9.97)], stent implantation [HR 3.61 (1.47-9.05)], hypertension [HR1.73 (1.06-2.21)], and eGFR [HR $0.99(0.98-1.00)]$ in ACS patients, and having triple vessel disease [HR 3.12 (1.43-6.82)], stent implantation [HR 4.10 (2.09-8.13)], hypertension [HR 
Table 2 Baseline characteristics and biochemical data of the study participants with and without major adverse cardiovascular events

\begin{tabular}{|c|c|c|c|c|}
\hline Variable & Total & With MACE & Without MACE & $P$-value \\
\hline No & 1520 & 558 & 962 & \\
\hline Age (years) & $68.9 \pm 12.0$ & $71.9 \pm 11.7$ & $67.2 \pm 11.9$ & $<0.0001$ \\
\hline Body mass index $\left(\mathrm{kg} / \mathrm{m}^{2}\right)$ & $25.7 \pm 10.6$ & $25.2 \pm 4.4$ & $26.0 \pm 12.9$ & 0.186 \\
\hline Waist circumference $(\mathrm{cm})$ & $91.0 \pm 10.4$ & $91.9 \pm 10.5$ & $90.4 \pm 10.2$ & 0.021 \\
\hline Waist to hip ratio & $0.94 \pm 0.11$ & $0.95 \pm 0.14$ & $0.93 \pm 0.08$ & $<0.0001$ \\
\hline Systolic BP (mmHg) & $133 \pm 22$ & $133 \pm 24$ & $132 \pm 21$ & 0.298 \\
\hline Diastolic BP (mmHg) & $77 \pm 14$ & $75 \pm 14$ & $77 \pm 13$ & 0.008 \\
\hline $\mathrm{HbA1C}(\%)$ & $7.0 \pm 1.8$ & $7.1 \pm 1.9$ & $6.9 \pm 1.7$ & 0.012 \\
\hline Fasting glucose (mg/dl) & $144.9 \pm 77.0$ & $159.5 \pm 88.7$ & $136.4 \pm 68.0$ & $<0.0001$ \\
\hline Total cholesterol (mg/dl) & $177.1 \pm 45.5$ & $174.9 \pm 45.3$ & $178.4 \pm 45.5$ & 0.156 \\
\hline Triglycerides (mg/dl) & $143.8 \pm 105.2$ & $138.1 \pm 93.3$ & $147.0 \pm 111.2$ & 0.116 \\
\hline HDL-cholesterol (mg/dl) & $40.2 \pm 12.0$ & $38.6 \pm 11.9$ & $41.0 \pm 12.0$ & 0.0002 \\
\hline LDL-cholesterol (mg/dl) & $103.7 \pm 35.4$ & $104.4 \pm 37.1$ & $103.2 \pm 34.3$ & 0.518 \\
\hline Creatinine (mg/dl) & $1.74 \pm 1.83$ & $2.0 \pm 2.3$ & $1.6 \pm 1.5$ & $<0.0001$ \\
\hline Uric acid (mg/dl) & $6.8 \pm 2.7$ & $7.0 \pm 2.1$ & $6.6 \pm 3.0$ & 0.017 \\
\hline $\operatorname{eGFR}\left(\mathrm{ml} / \mathrm{min} / 1.73 \mathrm{~m}^{2}\right)$ & $57.2 \pm 23.1$ & $51.4 \pm 23.0$ & $60.5 \pm 22.6$ & $<0.0001$ \\
\hline $\mathrm{Hs}-\mathrm{CRP}$ (mg/L) & $12.2 \pm 32.4$ & $14.0 \pm 36.8$ & $11.0 \pm 29.1$ & 0.001 \\
\hline White blood cell $\left(10^{9} /\right)$ & $8.469 \pm 3.877$ & $8.795 \pm 3.699$ & $8.279 \pm 3.967$ & 0.012 \\
\hline Red blood cell $(10 \% / \mu l)$ & $4.54 \pm 1.21$ & $4.46 \pm 0.94$ & $4.58 \pm 1.34$ & 0.030 \\
\hline Hemoglobin (g/dl) & $13.2 \pm 2.3$ & $13.1 \pm 2.6$ & $13.3 \pm 2.1$ & 0.033 \\
\hline Hematocrit (\%) & $39.5 \pm 6.1$ & $39.1 \pm 6.3$ & $39.8 \pm 5.9$ & 0.039 \\
\hline Mean corpuscular volume (fL) & $88.4 \pm 7.7$ & $88.6 \pm 7.9$ & $88.2 \pm 7.6$ & 0.320 \\
\hline MCH (pg/cell) & $29.8 \pm 7.4$ & $29.6 \pm 3.0$ & $30.0 \pm 9.1$ & 0.323 \\
\hline $\mathrm{MCHC}(\mathrm{g} / \mathrm{dL})$ & $33.4 \pm 1.3$ & $33.3 \pm 1.4$ & $33.5 \pm 1.2$ & $<0.0001$ \\
\hline Malnutrition indicator score & $24.7 \pm 3.5$ & $23.9 \pm 3.6$ & $25.1 \pm 3.3$ & 0.010 \\
\hline
\end{tabular}

Data are means \pm SD. MACE major adverse cardiovascular events, HDL-C high-density lipoprotein cholesterol LDL-C low-density lipoprotein cholesterol, $H s$-Crp high-sensitivity C-reactive protein, $M C H$ mean corpuscular hemoglobin, $M C H C$ mean corpuscular-hemoglobin concentration, eGFR= estimated glomerular filtration rate calculated by the chronic kidney disease-EPI two-level race equation [12]

$1.07(1.02-2.37)]$, and uric acid [HR 1.14 (1.01-1.28)] in elective PCI patients (Tables 3 and 4).

\section{AUC analysis}

We then evaluated the ability of triple vessel disease, stent implantation, hypertension, and eGFR or uric acid to predict the risk of MACE. In ACS patients, the AUC for triple vessel disease was $0.574(p<0.0001)$. When stent implantation, hypertension, and eGFR were added to this multivariate model, the AUC increased to 0.606 $(p=0.0004)$ for triple vessel disease and stent implantation, 0.615 for triple vessel disease, stent implantation, and hypertension, $0.655(p=0.004)$ for triple vessel disease, stent implantation, hypertension, and eGFR (Fig. 2a). In elective PCI patients, the AUC for triple vessel disease was $0.610(p<0.0001)$. When stent implantation, hypertension, and uric acid were added to this multivariate model, the AUC increased to 0.627 ( $p=$
0.045) for triple vessel disease and stent implantation, 0.644 for triple vessel disease, stent implantation, and hypertension, $0.678(p=0.001)$ for triple vessel disease, stent implantation, hypertension, and uric acid (Fig. 2b).

\section{Basic characteristics and biochemical data of the study participants with and without stent implantation}

In the present study, we found that stent implantation was associated with the development of MACE. Hence, we further subgrouped our study subjects according to their stent implantation status to examine what reason the stent implantation was associated with MACE. Table 5 lists the basic characteristics and biochemical data of the study participants with and without stent implantation. Patients with stent implantation were younger and had higher frequencies of male gender, triple vessel disease, and hyperlipidemia; higher BMI, HbA1C, total cholesterol, LDL-cholesterol, hs-CRP, and white 
Table 3 Cox proportional hazard model of baseline clinical risk factors for the development of major adverse cardiovascular events stratified by acute coronary syndrome and elective PCl subjects

\begin{tabular}{|c|c|c|c|c|c|c|c|c|}
\hline \multirow[b]{2}{*}{ Baseline data } & \multicolumn{4}{|c|}{ Acute coronary syndrome } & \multicolumn{4}{|l|}{ Elective PCl } \\
\hline & $\begin{array}{l}\text { Univariate analysis } \\
\text { HR }(95 \% \mathrm{Cl})\end{array}$ & $P$ value & $\begin{array}{l}\text { Multivariate model } \\
\text { HR }(95 \% \mathrm{Cl})\end{array}$ & $P$ value & $\begin{array}{l}\text { Univariate } \\
\text { analysis HR } \\
(95 \% \mathrm{Cl})\end{array}$ & $P$ value & $\begin{array}{l}\text { Multivariate model } \\
\text { HR }(95 \% \mathrm{Cl})\end{array}$ & $P$ value \\
\hline Age & $1.02(1.02-1.03)$ & $<0.0001$ & & & $1.03(1.01-1.04)$ & $<0.0001$ & & \\
\hline Gender & $1.10(0.85-1.45)$ & 0.486 & & & $1.15(0.88-1.54)$ & 0.317 & & \\
\hline Education (illiterate) & $1.63(1.19-2.18)$ & 0.002 & & & $1.25(0.85-1.79)$ & 0.257 & & \\
\hline Marital status (widow or widower) & $1.44(1.02-1.98)$ & 0.040 & & & $0.90(0.55-1.40)$ & 0.662 & & \\
\hline Malnourished & $2.87(0.86-7.21)$ & 0.082 & & & $4.00(1.20-9.91)$ & 0.027 & & \\
\hline Economic situation (dependent) & $1.52(1.18-1.97)$ & 0.001 & & & $1.81(1.34-2.45)$ & 0.0001 & & \\
\hline Smoking & $1.11(0.89-1.39)$ & 0.369 & & & $0.98(0.76-1.26)$ & 0.857 & & \\
\hline Drinking & $0.90(0.68-1.17)$ & 0.414 & & & $0.97(0.71-1.31)$ & 0.849 & & \\
\hline Regular exercise & $0.85(0.65-1.11)$ & 0.236 & & & $0.79(0.57-1.07)$ & 0.127 & & \\
\hline Antihypertensive medication & $0.98(0.78-1.24)$ & 0.885 & & & $0.95(0.73-1.22)$ & 0.661 & & \\
\hline Statins & $0.87(0.69-1.09)$ & 0.222 & & & $0.98(0.74-1.29)$ & 0.909 & & \\
\hline Hypoglycemic medication & $1.17(0.89-1.53)$ & 0.262 & & & $1.43(1.01-1.98)$ & 0.042 & & \\
\hline Triple vessel disease & $1.67(1.33-2.10)$ & $<0.0001$ & $3.66(1.38-9.97)$ & 0.009 & $2.27(1.75-2.93)$ & $<0.0001$ & $3.12(1.43-6.82)$ & 0.005 \\
\hline Stent implantation & $1.50(1.18-1.90)$ & 0.001 & $3.61(1.47-9.05)$ & 0.005 & $1.47(1.12-1.91)$ & 0.005 & $4.10(2.09-8.13)$ & 0.0001 \\
\hline Anemia & $1.42(1.10-1.81)$ & 0.007 & & & $1.47(1.09-1.95)$ & 0.011 & & \\
\hline Diabetes mellitus & $1.78(1.42-2.23)$ & $<0.0001$ & & & $1.35(1.04-1.74)$ & 0.024 & & \\
\hline Hypertension & $1.27(0.97-1.67)$ & 0.079 & $1.73(1.06-2.21)$ & 0.020 & $1.50(1.11-2.07)$ & 0.008 & $1.07(1.02-2.37)$ & 0.014 \\
\hline Hyperlipidemia & $0.99(0.78-1.28)$ & 0.960 & & & $1.03(0.79-1.34)$ & 0.839 & & \\
\hline
\end{tabular}

HR Hazard ratio, $P C l$ percutaneous coronary intervention

blood cell count; and lower frequencies of being a widow or widower than those without stent implantation patients.

\section{Discussion}

The goal of this study was to determine the predictors of MACE in Chinese patients with CAD who underwent $\mathrm{PCI}$ and/or stenting. Of the 1,520 consecutive patients evaluated, the incidence of MACE was $36.7 \%$ after a median duration of 23 months (interquartile range: 5-55 months) of follow-up. Triple vessel disease, stent implantation, hypertension, and eGFR or uric acid all contributed to the risk of a MACE between ACS and elective PCI patients. To the best of our knowledge, this study is the first observational clinical study to identify the independent risk factors for adverse cardiac events in a Chinese cohort of patients, who have distinct differences in presentation from those in western countries [17].

In addition to the most common predictors of MACE in CAD patients such as age [18], female gender [19], hypertension, number of stents placed [19-21], chronic heart failure [20], eGFR [22, 23], anemia [24], HDLcholesterol [25], and hs-CRP [26], the development of MACE in our population was further determined by triple vessel disease, stent implantation, hypertension, and eGFR or uric acid. Furthermore, we found that triple vessel disease, stent implantation, hypertension, and eGFR predicted the development of MACE in multivariate analysis, with an AUC of 0.655 in ACS patients, and triple vessel disease, stent implantation, hypertension, and uric acid predicted the development of MACE in multivariate analysis, with an AUC of 0.678 in elective PCI patients. In addition, consistent with several previous reports $[19,20]$ but in contrast to others [26-28], in the present study, DM did not predict the development of a MACE in our patients. Previous studies investigating the impact of DM on clinical outcomes yielded inconsistent results, which likely reflect differences in clinical diagnosis [29-31].

In the current study the levels of eGFR at baseline were inversely associated with the development of MACE in ACS patients, so a low eGFR may have higher risk of MACE, which is consistent with other studies where a lower eGFR was associated with the risk of death, cardiovascular events, and hospitalization [32, 33]. The mechanisms that underlie the association between renal dysfunction and CAD have not been elucidated fully. Previous studies have shown that renal dysfunction is associated with low-grade inflammation 
Table 4 Cox proportional hazard model of baseline biochemical risk factors for the development of major adverse cardiovascular events stratified by acute coronary syndrome and elective PCI subjects

\begin{tabular}{|c|c|c|c|c|c|c|c|c|}
\hline \multirow[b]{2}{*}{ Baseline data } & \multicolumn{4}{|c|}{ Acute coronary syndrome } & \multicolumn{4}{|l|}{ Elective $\mathrm{PCl}$} \\
\hline & $\begin{array}{l}\text { Univariate analysis } \\
\text { HR }(95 \% \mathrm{Cl})\end{array}$ & $P$ value & $\begin{array}{l}\text { Multivariate model HR } \\
(95 \% \mathrm{Cl})\end{array}$ & $P$-value & $\begin{array}{l}\text { Univariate analysis } \\
\text { HR }(95 \% \mathrm{Cl})\end{array}$ & $P$ value & $\begin{array}{l}\text { Multivariate model HR } \\
(95 \% \mathrm{Cl})\end{array}$ & $P$ value \\
\hline Body mass index & $0.98(0.95-1.01)$ & 0.135 & & & $0.99(0.97-1.03)$ & 0.942 & & \\
\hline Waist circumference & $1.01(0.99-1.02)$ & 0.131 & & & $1.01(0.99-1.02)$ & 0.172 & & \\
\hline Waist to hip ratio & $3.45(1.30-7.40)$ & 0.016 & & & $3.56(1.29-7.03)$ & 0.019 & & \\
\hline Systolic BP & $0.99(0.99-1.00)$ & 0.701 & & & $1.01(0.99-1.01)$ & 0.146 & & \\
\hline Diastolic BP & $0.24(0.07-0.90)$ & 0.034 & & & $0.15(0.02-0.97)$ & 0.046 & & \\
\hline $\mathrm{HbA} 1 \mathrm{C}$ & $1.06(0.99-1.11)$ & 0.063 & & & $1.06(0.99-1.16)$ & 0.192 & & \\
\hline Fasting glucose & $3.98(2.24-6.98)$ & $<0.0001$ & & & $3.82(1.85-7.66)$ & 0.0004 & & \\
\hline Total cholesterol & $0.43(0.24-0.91)$ & 0.030 & & & $1.04(0.30-3.61)$ & 0.946 & & \\
\hline Triglyceride & $0.99(0.99-1.00)$ & 0.121 & & & $0.99(0.99-1.00)$ & 0.154 & & \\
\hline HDL-cholesterol & $0.29(0.11-0.77)$ & 0.014 & & & $0.30(0.11-0.83)$ & 0.021 & & \\
\hline LDL-cholesterol & $1.00(0.99-1.00)$ & 0.447 & & & $1.00(0.99-1.01)$ & 0.221 & & \\
\hline Uric acid & $1.00(0.96-1.03)$ & 0.981 & & & $1.17(1.09-1.26)$ & $<0.0001$ & $1.14(1.01-1.28)$ & 0.041 \\
\hline Creatinine & $1.10(1.03-1.16)$ & 0.005 & & & $1.09(1.05-1.13)$ & 0.0004 & & \\
\hline eGFR & $0.46(0.32-0.66)$ & 0.0001 & $0.20(0.05-0.86)$ & 0.031 & $0.32(0.23-0.48)$ & $<0.0001$ & & \\
\hline $\mathrm{Hs}-\mathrm{CRP}$ & $1.00(0.99-1.01)$ & 0.713 & & & $1.01(1.00-1.01)$ & 0.013 & & \\
\hline White blood cell & $1.02(0.99-1.05)$ & 0.148 & & & $1.01(0.97-1.05)$ & 0.653 & & \\
\hline Red blood cell & $0.84(0.73-0.97)$ & 0.017 & & & $0.88(0.73-1.04)$ & 0.158 & & \\
\hline Hemoglobin & $0.93(0.89-0.98)$ & 0.004 & & & $0.95(0.89-1.02)$ & 0.143 & & \\
\hline Hematocrit & $0.98(0.96-0.99)$ & 0.003 & & & $0.98(0.95-1.00)$ & 0.073 & & \\
\hline MCV & $1.00(0.98-1.01)$ & 0.656 & & & $1.02(1.00-1.04)$ & 0.047 & & \\
\hline $\mathrm{MCH}$ & $0.97(0.94-1.01)$ & 0.099 & & & $1.00(0.97-1.01)$ & 0.687 & & \\
\hline $\mathrm{MCHC}$ & $0.91(0.84-0.99)$ & 0.029 & & & $0.89(0.81-0.98)$ & 0.016 & & \\
\hline
\end{tabular}

$\mathrm{PCl}$, percutaneous coronary intervention; $\mathrm{HR}$, hazard ratio; HDL-C, high-density lipoprotein cholesterol; LDL-C, low-density lipoprotein cholesterol; MCV, mean corpuscular volume; $\mathrm{MCH}$, mean corpuscular hemoglobin; $\mathrm{MCHC}$, mean corpuscular-hemoglobin concentration. eGFR= estimated glomerular filtration rate calculated by the chronic kidney disease-EPI two-level race equation [12]

and activation of the sympathetic nervous system or the rennin-angiotensinaldosterone system [34-36]. Foley et al. demonstrated that calcium-phosphate production and oxidative stress were shown to promote renal dysfunction [37]. Muntner et al. showed that apolipoprotein A1 levels are decreased and levels of homocysteine, lipoprotein (a), fibrinogen, and CRP are increased among patients with CKD [38]. These factors above could also contribute to the pathogenesis of atherosclerosis. Herzog and colleagues also described pressure overload, volume overload, and CKD associated non-hemodynamic factors that have enhanced CKD to alter the myocardium [39]. Renal insufficiency is an independent risk factor for cardiovascular outcomes and in-hospital and late mortality [40, 41]. Increased uremic toxins such as total indoxyl sulfate and $p$-cresylsulphate may be involved in the pathogenesis of coronary atherosclerosis, prolonged QTc interval, left ventricular systolic dysfunction, and elevated risk of MACE in CAD patients with low estimated glomerular filtration rate, and it is considered a coronary heart disease risk equivalent [42-46]. In addition, we found that uric acid was an independent risk factor for developing a MACE in elective PCI patients. Previous clinical investigations have demonstrated that hyperuricemia is an independent predictor of mortality in patients with cardiovascular disease [47-49]. Uric acid is the final oxidation product of purine catabolism in humans. It is formed from the breakdown of adenosine and guanine. When the purine breakdown products xanthine and hypoxanthine are converted to uric acid through the enzymatic action of xanthine oxidase, molecular oxygen is reduced and the free radical superoxide is generated. Oxygen-free radicals are postulated to play a key role in vascular injury in cardiovascular and kidney disease. George et al. suggested that uric acid was harm to endothelial function leading to cause of cardiovascular disease because uric acid levels may act as a marker of xanthine oxidase activity [50]. Previous studies have also shown that uric acid has directly contributed proliferative, 

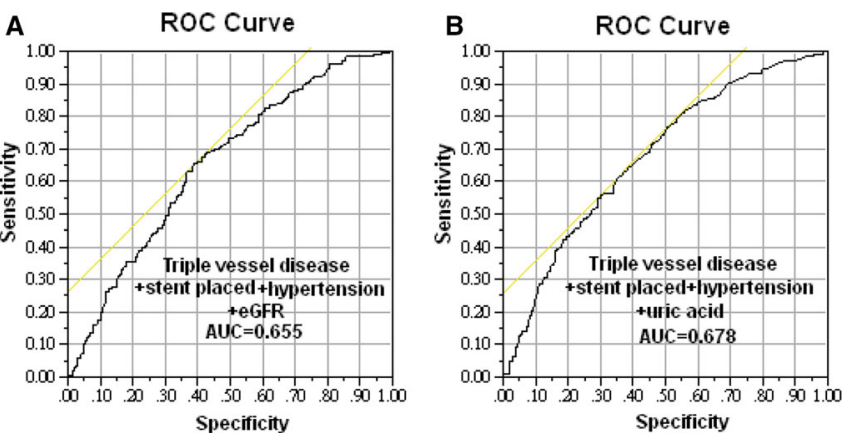

\begin{tabular}{lccc}
\hline Parameter & AUC & $\begin{array}{c}\text { Odds ratio } \\
(95 \% \mathrm{Cl})\end{array}$ & $\mathrm{p}$-value \\
\hline Triple vessel disease & 0.574 & $1.98(1.42-2.76)$ & $<0.0001$ \\
$\begin{array}{l}\text { Triple vessel disease } \\
\text { +stent implantation }\end{array}$ & 0.606 & $1.89(1.33-2.70)$ & 0.0004 \\
$\begin{array}{l}\text { Triple vessel disease } \\
\text { +stent implantation } \\
\text { +hypertension }\end{array}$ & 0.615 & $1.32(0.92-1.89)$ & 0.135 \\
$\begin{array}{l}\text { Triple vessel disease } \\
\text { +stent implantation } \\
\text { +hypertension }\end{array}$ & 0.655 & $1.63(1.17-2.29)$ & 0.004 \\
+eGFR & & & \\
\hline
\end{tabular}

\begin{tabular}{lccc}
\hline Parameter & AUC & $\begin{array}{c}\text { Odds ratio } \\
(95 \% \mathrm{Cl})\end{array}$ & p-value \\
\hline Triple vessel disease & 0.610 & $2.94(2.13-4.07)$ & $<0.0001$ \\
$\begin{array}{l}\text { Triple vessel disease } \\
\text { +stent implantation }\end{array}$ & 0.627 & $1.21(1.07-1.68)$ & 0.045 \\
$\begin{array}{l}\text { Triple vessel disease } \\
\text { +stent implantation } \\
\text { +hypertension }\end{array}$ & 0.644 & $1.76(1.23-2.55)$ & 0.002 \\
$\begin{array}{l}\text { Triple vessel disease } \\
\text { +stent implantation } \\
\text { +hypertension } \\
\text { +uric acid }\end{array}$ & 0.678 & $4.87(1.87-12.65)$ & 0.001 \\
\hline
\end{tabular}

Fig. 2 Comparison of the receiver operating characteristic (ROC) curves with area under the curves (AUC) for the risk of major adverse cardiac events (MACE) of acute coronary syndrome subjects with four factors (triple vessel disease, stent implantation, hypertension, and estimated glomerular filtration rate (eGFR)). The AUC using triple vessel disease was calculated first, then stent implantation was added to this model, and then hypertension and eGFR (a). In addition, comparison of the ROC curves with area under the curves (AUC) for the risk of MACE of elective percutaneous coronary interventions subjects with four factors (triple vessel disease, stent implantation, hypertension, and uric acid). The AUC using triple vessel disease was calculated first, then stent implantation was added to this model, and then hypertension and uric acid (b)

proinflammatory, and proatherogenic effects on human vascular smooth muscle cells and endothelial cells through upregulate CRP, an active component in the inflammatory process, which can lead to both hypertension and vascular disease [51-53]. Taken together, these findings highlight the clinical and public health importance of chronic renal insufficiency and hyperuricemia.

In this study, we found that hypertension was an independent risk factor for developing a MACE not only in ACS patients but also in elective PCI patients. This is consistent with reports in which a history of hypertension was one of the risk factors for a MACE [21, 54]. Madan et al. enrolled 9,494 patients and found that hypertension was an independent predictor of adverse cardiac events after PCI [20]. In the other hand, chronic hypertension is also one of the important cardiovascular risk factors for development of atherosclerosis [55] and an increased incidence of CAD [56], CKD [57], peripheral vascular disease [58], and cerebrovascular disease [59]. Moreover, hypertension is also known as an important risk factor for myocardial infarction, stroke, heart failure, and cardiovascular death $[60,61]$. The relation between hypertension and myocardial infarction could be explained underscoring two key factors: (1) common risk factors, such as sympathetic hyperactivity, insulin resistance, vasoactive substances (i.e., angiotensin II), and genetic risk profiles and (2) hypertension is a risk factor of atherosclerosis, which contributes to progression of myocardial infarction [62]. Genetic risk factors such as gene polymorphisms of the angiotensinogen-converting enzyme and of the renin-angiotensin-aldosterone system, could cause myocardial infarction, hypertension, and cardiovascular complications [63, 64]. Furthermore, in hypertensive patients, a hyperactivity of sympathetic tone which causes sympathetic vasoconstriction on glucose extraction in skeletal muscle, beta-adrenergic receptor-mediated insulin resistance, and vascular rarefaction; may contribute atherosclerosis by worsening insulin resistance. Previous study suggested that sympathetic hyperactivity itself also contributes higher risk of coronary spasm, coronary thrombosis, and sudden death [65].

Besides the classical risk factors, others risk factors may also influence the development of MACE [20]. In the present study, we also found that triple vessel disease and stent implantation were associated with the development of MACE. Studies by Chow et al. and de Waha et al. both reported that the severity of CAD and multivessel CAD not only predicted all-cause mortality but also were high-risk factors for adverse clinical outcomes [66, 67]. The higher morbidity and mortality are seen in STsegment elevation myocardial infarction patients with multi-vessel CAD. The mechanism is multifactorial, including total ischemic burden, the presence of diffuse atherosclerosis as a harbinger of plaque instability, and 
Table 5 Baseline characteristics and biochemical data of the study participants with and without stent implantation

\begin{tabular}{|c|c|c|c|}
\hline Variable & With stent implantation & Without stent implantation & $P$-value \\
\hline No & 458 & 1062 & \\
\hline Age (years) & $67.2 \pm 11.1$ & $69.5 \pm 12.3$ & 0.001 \\
\hline Gender (male) & $352(76.9)$ & $751(70.7)$ & 0.004 \\
\hline Education (illiterate) & $62(13.5)$ & 194(18.3) & 0.053 \\
\hline Marital status (widow or widower) & $41(9.0)$ & 145(13.7) & 0.028 \\
\hline Malnourished & $11(2.4)$ & $49(4.6)$ & 0.406 \\
\hline Economic situation (dependent) & 215(46.9) & $552(52.0)$ & 0.128 \\
\hline Smoking & 235(51.3) & $490(46.1)$ & 0.077 \\
\hline Triple vessel disease & 174(38.0) & 254(23.9) & $<0.0001$ \\
\hline Anemia & $103(22.5)$ & $249(23.5)$ & 0.661 \\
\hline Diabetes mellitus & 188(41.1) & $396(37.3)$ & 0.168 \\
\hline Hypertension & $341(74.5)$ & 750(70.6) & 0.137 \\
\hline Hyperlipidemia & $335(73.1)$ & $613(57.7)$ & $<0.0001$ \\
\hline Body mass index $\left(\mathrm{kg} / \mathrm{m}^{2}\right)$ & $26.7 \pm 18.5$ & $25.3 \pm 4.4$ & 0.017 \\
\hline Systolic BP (mmHg) & $133 \pm 21$ & $132 \pm 22$ & 0.864 \\
\hline Diastolic BP (mmHg) & $77 \pm 13$ & $76 \pm 14$ & 0.242 \\
\hline $\mathrm{HbA} 1 \mathrm{C}(\%)$ & $7.1 \pm 1.7$ & $6.9 \pm 1.8$ & 0.048 \\
\hline Fasting glucose (mg/dl) & $146.0 \pm 75.5$ & $144.3 \pm 77.6$ & 0.700 \\
\hline Total cholesterol (mg/dl) & $180.7 \pm 46.6$ & $175.4 \pm 44.7$ & 0.039 \\
\hline Triglycerides (mg/dl) & $148.6 \pm 108.1$ & $141.3 \pm 103.0$ & 0.220 \\
\hline HDL-cholesterol (mg/dl) & $39.4 \pm 12.7$ & $40.5 \pm 11.8$ & 0.110 \\
\hline LDL-cholesterol (mg/dl) & $106.7 \pm 37.8$ & $102.1 \pm 34.0$ & 0.023 \\
\hline Creatinine (mg/dl) & $1.9 \pm 2.4$ & $1.7 \pm 1.5$ & 0.090 \\
\hline Uric acid (mg/dl) & $6.9 \pm 3.7$ & $6.8 \pm 2.2$ & 0.622 \\
\hline $\mathrm{eGFR}\left(\mathrm{ml} / \mathrm{min} / 1.73 \mathrm{~m}^{2}\right)$ & $57.8 \pm 22.7$ & $57.3 \pm 23.2$ & 0.686 \\
\hline $\mathrm{Hs}-\mathrm{CRP}(\mathrm{mg} / \mathrm{L})$ & $13.6 \pm 35.5$ & $9.0 \pm 24.2$ & 0.044 \\
\hline White blood cell $\left(10^{9} /\right)$ & $8.652 \pm 4.151$ & $8.010 \pm 3.128$ & 0.004 \\
\hline Red blood cell $\left(10^{6} / \mu \mathrm{l}\right)$ & $4.54 \pm 0.85$ & $4.54 \pm 1.33$ & 0.952 \\
\hline Hemoglobin (g/dl) & $13.3 \pm 2.1$ & $13.2 \pm 2.3$ & 0.482 \\
\hline Hematocrit (\%) & $39.7 \pm 5.6$ & $39.5 \pm 6.2$ & 0.720 \\
\hline
\end{tabular}

Data are means $\pm S D$ or number (\%). HDL-C high-density lipoprotein cholesterol, $L D L-C$ low-density lipoprotein cholesterol; $H s$-CRP high-sensitivity C-reactive protein. eGFR = estimated glomerular filtration rate calculated by the chronic kidney disease-EPI two-level race equation [12]

impaired contractility of non-infarct zones in the presence of multiple obstructive stenosis [68]. Interestingly, in our study, the stent implantation was found to be a surrogate marker of MACE. When we further subgrouped our study subjects according to their stent implantation status, the results found that patients with stent implantation had higher rates of triple vessel disease and hyperlipidemia; higher BMI, $\mathrm{HbA} 1 \mathrm{C}$, total cholesterol, LDL-cholesterol, hs-CRP, and white blood cell count than those without stent implantation patients. Hyperlipidemia and obesity are recognized as a risk factor for CAD and coronary mortality [69, 70]. Furthermore, several reports have suggested that delayed arterial healing and vessel remodeling due to chronic inflammation have been reported as reasons for the high rates of very late stent thrombosis with drug-eluting stent [71-75]. Previously, studies have indicated that this reduction in restenosis might have been obtained at the expense of a higher incidence of stent thrombosis that links stent implantation and adverse cardiac events such as recurrent myocardial infarction or death $[76,77]$. Hence, we think multifactorial occurrence, including triple vessel disease, hyperlipidemia, higher BMI, HbA1C, and inflammation response that promote the association of stent implantation with the MACE in our study $[66,67,69,70,75,78]$. In addition, there was no statistically significant difference in rate of MACE among 4 operators in the present study. This 
indicated that operators issue did not affect the finding of stent implantation association with MACE.

There are several limitations to this study. First, the results may be skewed by procedural preferences and the patients seen at our institution. Second, we did not assess several complications that are common after PCI such as contrast nephropathy and access-site vascular complications. Third, we did not examine the relationship between operator procedure volume and cardiac complications. Four, this is an observational study in only one centre. Hence, further work is required to confirm these findings in populations of different races and these exploratory results should be confirmed in a larger study and other centre. Finally, although the current model has been validated for the contemporary practice of PCI, further advances in PCI techniques and technology may reduce the discriminatory ability and predictive accuracy of the model. Thus, the model may need to be recalibrated in the future.

\section{Conclusion}

The present study indicates that having triple vessel disease, stent implantation, hypertension, and eGFR or uric acid levels independently predicted the development of MACE in patients with CAD after long-term follow-up. We suggest that uric acid, eGFR, and blood pressure should be closely monitored in patients with CAD.

\section{Abbreviations \\ ACS: acute coronary syndrome; AUC: area under the curves; BMI: body mass index:; CABG: coronary artery bypass graft; CAD: Coronary artery disease; CKD: Chronic kidney disease; eGFR: Estimated glomerular filtration rate; HbA1c: Hemoglobin A1c; HDL: High-density lipoprotein; HF: Heart failure; CRP: C-reactive protein; HR: Hazard ratio; LDL: Low-density lipoprotein; MACE: Major adverse cardiac events; MCHC: Mean corpuscular-hemoglobin concentration; MI: Myocardial infarction; PCI: Percutaneous coronary intervention; RBC: Red blood cell; ROC: Receiver operating characteristic; WBC: White blood cell; WHR: Waist to hip ratio}

\section{Acknowledgments}

We are grateful to the staff and members of the heart care teams for their assistance with various measurements and other organizational aspects of this study.

\section{Funding}

This work was supported by grants from the E-Da Hospital of the Republic of China, Taiwan (contract no. EDAHP-104064).

\section{Availability of data and materials}

We are regret that according to the regulation of our institute research ethics committees and institutional review boards, the details data of the study subjects could not be disclosure publicly. However, the data set is allowed to be requested and examined by any journal reviewer board under request and after the institute ethics committee's agreement.

\section{Authors' contributions}

Of the 10 authors, I-TT is the first author who conceived and designed the study and interpreted the data. Y-CL, C-CH, C-PW, W-CH, and Y-JL contributed to drafting of the manuscript or revising it critically for important intellectual content. L-FL and C-CW acquired data, drafted the manuscript and designed the study. Dr. F-MC participated in the design of the study and performed the statistical analysis. Dr. T-HY is the corresponding author and contributed to the final approval of the manuscript as submitted. All authors read and approved the final version of the manuscript.

\section{Competing interests}

The authors declare that they have no competing interests.

\section{Consent for publication}

Not applicable.

\section{Ethics approval and consent to participate}

The ethics committee of I-Shou University E-Da Hospital approved this study (EDAH IRB No. EMRP-103-095). All patients gave written consent to participate in this study.

\section{Author details}

'Department of Emergency, E-Da Hospital, I-Shou University, Kaohsiung 82445, Taiwan. ${ }^{2}$ Division of Cardiology, E-Da Hospital, I-Shou University, No. 1 Yi-Da Rd, Jiau-Shu Village, Yan-Chao District, Kaohsiung 82445, Taiwan. ${ }^{3}$ Division of Endocrinology and Metabolism, E-Da Hospital, I-Shou University, Kaohsiung 82445, Taiwan. ${ }^{4}$ Division of Gastroenterology and Hepatology, Department of Internal Medicine, E-Da Hospital, I-Shou University, Kaohsiung 82445, Taiwan. ${ }^{5}$ Division of Cardiac Surgery, Department of Surgery, E-Da Hospital, I-Shou University, Kaohsiung 82445, Taiwan. 'Lee's Endocrinology Clinic, Pingtung 90000, Taiwan. ${ }^{7}$ School of Medicine for International Students, E-Da Hospital, I-Shou University, Kaohsiung 82445, Taiwan. ${ }^{8}$ Department of Nursing, I-Shou University, Kaohsiung 82445, Taiwan. ${ }^{9}$ Department of Biomedical Engineering, National Cheng Kung University, Tainan 70101, Taiwan.

Received: 31 March 2016 Accepted: 7 December 2016

Published online: 04 January 2017

\section{References}

1. Directorate-general of budget, accounting and statistics Executive Yuan, Republic of China Statistical Yearbook of the Republic of China. Health. 2010;114:109-116.

2. Chen $\mathrm{CL}$, Chen L, Yang WC. The influences of Taiwan's generic grouping price policy on drug prices and expenditures: Evidence from analysing the consumption of the three most-used classes of cardiovascular drugs. BMC Public Health. 2008;8:118.

3. Murray CJ, Lopez AD. Alternative projections of mortality and disability by cause 1990-2020: Global burden of disease study. Lancet. 1997;349:1498-504.

4. Deb S, Wijeysundera HC, Ko DT, Tsubota H, Hill S, Fremes SE. Coronary artery bypass graft surgery vs percutaneous interventions in coronary revascularization: a systematic review. JAMA. 2013;310:2086-95.

5. Schömig A, Mehilli J, de Waha A, Seyfarth M, Pache J, Kastrati A. A metaanalysis of 17 randomized trials of a percutaneous coronary interventionbased strategy in patients with stable coronary artery disease. J Am Coll Cardiol. 2008;52:894-904

6. Daemen J, Boersma E, Flather M, Booth J, Stables R, Rodriguez A, et al. Long- term safety and efficacy of percutaneous coronary intervention with stenting and coronary artery bypass surgery for multivessel coronary artery disease: a meta-analysis with 5-year patient-level data from the ARTS, ERACIII, MASS-II, and SoS trials. Circulation. 2008;118:1146-54.

7. Yusuf S, Hawken S, Ounpuu S, Dans T, Avezum A, Lanas F, et al. INTERHEART Study Investigators. Effect of potentially modifiable risk factors associated with myocardial infarction in 52 countries (the INTERHEART study): case-control study. Lancet. 2004;364:937-52.

8. Chhatriwalla AK, Nicholls SJ, Wang TH, Wolski K, Sipahi I, Crowe T, et al. Low levels of low-density lipoprotein cholesterol and blood pressure and progression of coronary atherosclerosis. J Am Coll Cardiol. 2009;53:1110-5.

9. Bayturan O, Kapadia S, Nicholls SJ, Tuzcu EM, Shao M, Uno K, et al. Clinical predictors of plaque progression despite very low levels of low-density lipoprotein cholesterol. J Am Coll Cardiol. 2010;55:2736-42.

10. Schoenenberger AW, Jamshidi P, Kobza R, Zuber M, Stuck AE, Pfisterer M, et al. Progression of coronary artery disease during long-term follow-up of the Swiss Interventional Study on Silent Ischemia Type II (SWISSI II). Clin Cardiol. 2010;33:289-95.

11. Hung WC, Yu TH, Hsu CC, Lu LF, Chung FM, Tsai IT, et al. Plasma visfatin levels are associated with major adverse cardiovascular events in patients with acute ST-elevation myocardial infarction. Clin Invest Med. 2015;38: E100-9. 
12. Kong X, Ma Y, Chen J, Luo Q, Yu X, Li Y, et al. Chinese eGFR Investigation Collaboration. Evaluation of the Chronic Kidney Disease Epidemiology Collaboration equation for estimating glomerular filtration rate in the Chinese population. Nephrol Dial Transplant. 2013;28:641-51.

13. Califf RM, Bengtson JR. Cardiogenic shock. N Engl J Med. 1994;330:1724-30.

14. Expert Panel on Detection, Evaluation, and Treatment of High Blood Cholesterol in Adults. Executive summary of the third report of the National Cholesterol Education Program (NCEP) Expert Panel on Detection, Evaluation, And Treatment of High Blood Cholesterol In Adults (Adult Treatment Panel III). JAMA. 2001;285:2486-97.

15. American Diabetes Association. Diagnosis and classification of diabetes mellitus. Diabetes Care. 2012;35 Suppl 1:S64-71.

16. Hanley JA, McNeil BJ. The meaning and use of the area under a receiver operating characteristic (ROC) curve. Radiology. 1982;143:29-36.

17. Brieger DB, Chew DP, Redfern J, Ellis C, Briffa TG, Howell TE, et al. Survival after an acute coronary syndrome: 18-month outcomes from the Australian and New Zealand SNAPSHOT ACS study. Med J Aust. 2015;203:368.

18. Bae MH, Lee JH, Yang DH, Park HS, Cho Y, Chae SC. Usefulness of surgical parameters as predictors of postoperative cardiac events in patients undergoing non-cardiac surgery. Circ J. 2014;78:718-23.

19. Xu L, Yu C, Jiang J, Zheng H, Yao S, Pei L, et al. Major adverse cardiac events in elderly patients with coronary artery disease undergoing noncardiac surgery: A multicenter prospective study in China. Arch Gerontol Geriatr. 2015;61:503-9.

20. Madan P, Elayda MA, Lee W, Wilson JM. Predicting major adverse cardiac events after percutaneous coronary intervention: the Texas Heart Institute risk score. Am Heart J. 2008;155:1068-74.

21. Omstedt Å, Höijer J, Djärv T, Svensson P. Hypertension predicts major adverse cardiac events after discharge from the emergency department with unspecified chest pain. Eur Heart J Acute Cardiovasc Care. 2016, in press.

22. Huang H, Zeng C, Ma Y, Chen Y, Chen C, Liu C, et al. Effects of Long-Term Statin Therapy in Coronary Artery Disease Patients with or without Chronic Kidney Disease. Dis Markers. 2015;2015:252564.

23. Édes IF, Ruzsa Z, Szabó G, Nardai S, Becker D, Benke K, et al. Clinical predictors of mortality following rotational atherectomy and stent implantation in high-risk patients: A single center experience. Catheter Cardiovasc Interv. 2015;86:634-41.

24. Wang X, Qiu M, Li J, Wang H, Qi J, Wang G, et al. Impacts of anemia on 3year ischemic events in patients undergoing percutaneous coronary intervention: a propensity-matched study. J Thorac Dis. 2015;7:1951-9.

25. Lu Q, Tian G, Zhang Y, Lu M, Lin X, Ma A. Low HDL-C predicts risk and PCl outcomes in the Han Chinese population. Atherosclerosis. 2013;226:193-7.

26. Pan HC, Sheu WH, Lee WJ, Lee WL, Liao YC, Wang KY, et al. Coronary severity score and C-reactive protein predict major adverse cardiovascular events in patients with stable coronary artery disease (from the Taichung CAD study). Clin Chim Acta. 2015;445:93-100.

27. Elezi S, Kastrati A, Pache J, Wehinger A, Hadamitzky M, Dirschinger J, et al. Diabetes mellitus and the clinical and angiographic outcome after coronary stent placement. J Am Coll Cardiol. 1998;32:1866-73.

28. Zhu L, Liu J, Gao C, Zhao W, Que J, Wang X, et al. Comparison of coronary plaque, coronary artery calcification and major adverse cardiac events in Chinese outpatients with and without type 2 diabetes. Springerplus. 2016; 5(1):1678.

29. Park DW, Flaherty JD, Davidson CJ, Yun SC, Lee SW, Kim YH, et al. Prognostic influence of diabetes mellitus on long-term clinical outcomes and stent thrombosis after drug-eluting stent implantation in Asian patients. Am J Cardiol. 2009;103:646-52.

30. Lee MS, Jurewitz D, Zimmer R, Pessegueiro A, Bhatia R, Currier J, et al. Impact of diabetes and acute coronary syndrome on survival in patients treated with drug-eluting stents. Catheter Cardiovasc Interv. 2008;72:909-14.

31. Kedhi $E$, Généreux $P$, Palmerini $T$, McAndrew TC, Parise $H$, Mehran $R$, et al. Impact of coronary lesion complexity on drug-eluting stent outcomes in patients with and without diabetes mellitus: analysis from 18 pooled randomized trials. J Am Coll Cardiol. 2014;63:2111-8.

32. Go AS, Chertow GM, Fan D, McCulloch CE, Hsu CY. Chronic kidney disease and the risks of death, cardiovascular events, and hospitalization. N Engl J Med. 2004;351:1296-305

33. Anavekar NS, McMurray JJ, Velazquez EJ, Solomon SD, Kober L, Rouleau JL, et al. Relation between renal dysfunction and cardiovascular outcomes after myocardial infarction. N Engl J Med. 2004;351:1285-95.
34. Schiffrin EL, Lipman ML, Mann JF. Chronic kidney disease: Effects on the cardiovascular system. Circulation. 2007;116:85-97.

35. Manabe I. Chronic inflammation links cardiovascular, metabolic and renal diseases. Circ J. 2011:75:2739-48.

36. Iwanaga Y, Miyazaki S. Heart failure, chronic kidney disease, and biomarkers: An integrated viewpoint. Circ J. 2010;74:1274-82.

37. Foley RN, Collins AJ, Ishani A, Kalra PA. Calcium-phosphate levels and cardiovascular disease in community-dwelling adults: The atherosclerosis risk in communities (ARIC) study. Am Heart J. 2008;156:556-63.

38. Muntner P, Hamm LL, Kusek JW, Chen J, Whelton PK, He J. The prevalence of nontraditional risk factors for coronary heart disease in patients with chronic kidney disease. Ann Intern Med. 2004;140:9-17.

39. Herzog CA, Asinger RW, Berger AK, Charytan DM, Díez J, Hart RG, et al. Cardiovascular disease in chronic kidney disease. A clinical update from Kidney Disease: Improving Global Outcomes (KDIGO). Kidney Int. 2011; 80:572-86.

40. Kwok CS, Hulme W, Olier I, Holroyd E, Mamas MA. Review of early hospitalisation after percutaneous coronary intervention. Int J Cardiol. 2016. doi:10.1016/j.jicard.2016.11.050. [Epub ahead of print].

41. Chew DP, Astley C, Molloy D, Vaile J, De Pasquale CG, Aylward P. Morbidity, mortality and economic burden of renal impairment in cardiac intensive care. Intern Med J. 2006;36:185-92.

42. Wang CP, Lu LF, Yu TH, Hung WC, Chiu CA, Chung FM, et al. Associations among chronic kidney disease, high total p-cresylsulfate and major adverse cardiac events. J Nephrol. 2013;26:111-8.

43. Wang CP, Lu LF, Yu TH, Hung WC, Chiu CA, Chung FM, et al. Serum levels of total p-cresylsulphate are associated with angiographic coronary atherosclerosis severity in stable angina patients with early stage of renal failure. Atherosclerosis. 2010;211:579-83.

44. Tang WH, Wang CP, Chung FM, Huang LL, Yu TH, Hung WC, et al. Uremic retention solute indoxyl sulfate level is associated with prolonged QTC interval in early CKD patients. PLoS One. 2015;10:e0119545.

45. Lu LF, Tang WH, Hsu CC, Tsai IT, Hung WC, Yu TH, et al. Associations among chronic kidney disease, high total p-cresylsulfate and left ventricular systolic dysfunction. Clin Chim Acta. 2016;457:63-8.

46. Hsu CC, Lu YC, Chiu CA, Yu TH, Hung WC, Wang CP, et al. Levels of indoxyl sulfate are associated with severity of coronary atherosclerosis. Clin Invest Med. 2013;36:E42-9.

47. loachimescu AG, Brennan DM, Hoar BM, Hazen SL, Hoogwerf BJ. Serum uric acid is an independent predictor of all-cause mortality in patients at high risk of cardiovascular disease. Arthritis Rheum. 2008;58:623-30.

48. Fang J, Alderman $\mathrm{MH}$. Serum uric acid and cardiovascular mortality the NHANES I epidemiologic follow-up study, 1971-1992. National Health and Nutrition Examination Survey. JAMA. 2000;283:2404-10.

49. Niskanen LK, Laaksonen DE, Nyyssönen K, Alfthan G, Lakka HM, Lakka TA, et al. Uric acid level as a risk factor for cardiovascular and all-cause mortality in middleaged men: A prospective cohort study. Arch Intern Med. 2004;164:1546-51.

50. George J, Carr E, Davies J, Belch JJ, Struthers A. High-dose allopurinol improves endothelial function by profoundly reducing vascular oxidative stress and not by lowering uric acid. Circulation. 2006;114:2508-16.

51. Kang DH, Park SK, Lee IK, Johnson RJ. Uric acid induced C-reactive protein (CRP) expression: Implication on cell proliferation and nitric oxide production in human vascular cells. J Am Soc Nephrol. 2005;16:3553-62.

52. Rao GN, Corson MA, Berk BC. Uric acid stimulates vascular smooth muscle cell proliferation by increasing plateletderived growth factor A-chain expression. J Biol Chem. 1991;266:8604-8.

53. Kang DH, Han L, Ouyang X, Kahn AM, Kanellis J, Li P, et al. Uric acid causes vascular smooth muscle cell proliferation by entering cells via a functional urate transporter. Am J Nephrol. 2005;25:425-33.

54. Howell SJ, Sear YM, Yeates D, Goldacre M, Sear JW, Foëx P. Risk factors for cardiovascular death after elective surgery under general anaesthesia. Br J Anaesth. 1998:80:14-9.

55. Dzau VJ. Atherosclerosis and hypertension: mechanisms and interrelationships. J Cardiovasc Pharmacol. 1990;15 Suppl 5:S59-64.

56. Levy D, Wilson PW, Anderson KM, Castelli WP. Stratifying the patient at risk from coronary disease: new insights from the Framingham Heart Study. Am Heart J. 1990;119:712-7.

57. Adamczak M, Zeier M, Dikow R, Ritz E. Kidney and hypertension. Kidney Int Suppl. 2002;80:62-7.

58. Murabito JM, D'Agostino RB, Silbershatz H, Wilson WF. Intermittent claudication. A risk profile from The Framingham Heart Study. Circulation. 1997;96:44-9. 
59. Lewington S, Clarke R, Qizilbash N, Peto R. Collins R; Prospective Studies Collaboration. Age-specific relevance of usual blood pressure to vascular mortality: a meta-analysis of individual data for one million adults in 61 prospective studies. Lancet. 2002;360:1903-13.

60. Richards AM, Nicholls MG, Troughton RW, Lainchbury JG, Elliott J, Frampton C, et al. Antecedent hypertension and heart failure after myocardial infarction. J Am Coll Cardiol. 2002;39:1182-8.

61. Miura K, Daviglus ML, Dyer AR, Liu K, Garside DB, Stamler J, et al. Relationship of blood pressure to 25-year mortality due to coronary heart disease, cardiovascular diseases, and all causes in young adult men: the Chicago Heart Association Detection Project in Industry. Arch Intern Med. 2001; 161:1501-8.

62. Rakugi H, Yu H, Kamitani A, Nakamura Y, Ohishi M, Kamide K, et al. Links between hypertension and myocardial infarction. Am Heart J. 1996;132:213-21.

63. Hata A, Namikawa C, Sasaki M, Sato K, Nakamura T, Tamura K, et al. Angiotensinogen as a risk factor for essential hypertension in Japan. J Clin Invest. 1994;93:1285-7.

64. Iwai N, Shimoike H, Ohmichi N, Kinoshita M. Angiotensinogen gene and blood pressure in the Japanese population. Hypertension. 1995;25:688-93.

65. Julius S. Corcoran Lecture. Sympathetic hyperactivity and coronary risk in hypertension. Hypertension. 1993;21:886-93.

66. Chow BJ, Wells GA, Chen L, Yam Y, Galiwango P, Abraham A, et al. Prognostic value of 64 -slice cardiac computed tomography severity of coronary artery disease, coronary atherosclerosis, and left ventricular ejection fraction. J Am Coll Cardiol. 2010;55:1017-28.

67. de Waha S, Eitel I, Desch S, Fuernau G, Pöss J, Schuler G, et al. Impact of multivessel coronary artery disease on reperfusion success in patients with ST-elevation myocardial infarction: A substudy of the AIDA STEMI trial. Eur Heart J Acute Cardiovasc Care. 2015, in press.

68. Goldstein JA, Demetriou D, Grines CL, Pica M, Shoukfeh M, O'Neill WW. Multiple complex coronary plaques in patients with acute myocardial infarction. N Engl J Med. 2000;343:915-22.

69. National Cholesterol Education Program. Second Report of the Expert Panel on Detection, Evaluation, and Treatment of High Blood Cholesterol in Adults (Adult Treatment Panel II). Circulation. 1994:89:1333-445.

70. Sharma S, Batsis JA, Coutinho T, Somers VK, Hodge DO, Carter RE, et al. Normal-Weight Central Obesity and Mortality Risk in Older Adults With Coronary Artery Disease. Mayo Clin Proc. 2016;91:343-51.

71. Kotani J, Awata M, Nanto S, Uematsu M, Oshima F, Minamiguchi H, et al. Incomplete neointimal coverage of sirolimus-eluting stents: Angioscopic findings. J Am Coll Cardiol. 2006;47:2108-11.

72. Awata M, Kotani J, Uematsu M, Morozumi T, Watanabe T, Onishi T, et al. Serial angioscopic evidence of incomplete neointimal coverage after sirolimus-eluting stent implantation: Comparison with baremetal stents. Circulation. 2007;116:910-6

73. Alfonso F, Pérez-Vizcayno MJ, Ruiz M, Suárez A, Cazares M, Hernández R, et al. Coronary aneurysms after drug-eluting stent implantation: Clinical, angiographic, and intravascular ultrasound findings. J Am Coll Cardiol. 2009; 53:2053-60.

74. Guagliumi G, Costa MA, Sirbu V, Musumeci G, Bezerra HG, Suzuki N, et al. Strut coverage and late malapposition with paclitaxel-eluting stents compared with bare metal stents in acute myocardial infarction: Optical coherence tomography substudy of the Harmonizing Outcomes with Revascularization and Stents in Acute Myocardial Infarction (HORIZONS-AMI) Trial. Circulation. 2011;123:274-81.

75. Virmani R, Guagliumi G, Farb A, Musumeci G, Grieco N, Motta T, et al. Localized hypersensitivity and late coronary thrombosis secondary to a sirolimus-eluting stent: Should we be cautious? Circulation. 2004;109:701-5.

76. Cutlip DE, Baim DS, Ho KK, Popma JJ, Lansky AJ, Cohen DJ, et al. Stent thrombosis in the modern era: a pooled analysis of multicenter coronary stent clinical trials. Circulation. 2001;103:1967-71.

77. Ong AT, Hoye A, Aoki J, van Mieghem CA, Rodriguez Granillo GA, Sonnenschein $\mathrm{K}$, et al. Thirty-day incidence and six-month clinical outcome of thrombotic stent occlusion after bare-metal, sirolimus, or paclitaxel stent implantation. J Am Coll Cardiol. 2005:45:947-53.

78. Tsai JP, Tian J, Wang WY, Ng AC. Glycated hemoglobin vs fasting plasma glucose as a predictor of left ventricular dysfunction after ST-elevation myocardial infarction. Can J Cardiol. 2015;31:44-9.

\section{Submit your next manuscript to BioMed Central and we will help you at every step:}

- We accept pre-submission inquiries

- Our selector tool helps you to find the most relevant journal

- We provide round the clock customer support

- Convenient online submission

- Thorough peer review

- Inclusion in PubMed and all major indexing services

- Maximum visibility for your research

Submit your manuscript at www.biomedcentral.com/submit
( ) BioMed Central 